\title{
REVIEWS
}

\section{Wolf-Hirschhorn Syndrome (WHS) - Literature Review on the Features of the Syndrome}

\author{
Department of Dentofacial Anomalies, Department of Orthodontics, Wroclaw Medical University, Poland
}

\begin{abstract}
Wolf-Hirschhorn syndrome (WHS) is a congenital disorder associated with 4 chromosome microdeletion. The patients suffer from various deformities. Among them, mental and growth retardation, even in the fetus, are observed. Most of the characteristics concern facial features. The "Greek warrior helmet appearance" is the most characteristic feature and refers to the facial view with prominent glabella, high arched eyebrow, broad nasal bridge and hypertelorism. Another characteristic feature is microcephalia with micrognathia. The features are more pronounced in infants. Clefts of lip and/or palate are observed in almost half of the cases. The characteristic thing is that the more genetic material is missing, the more pronounced are the dimorphic features of the syndrome. Mostly, the dental status does not differ much from that of the healthy individuals. It had been proven though that WHS-patients are more prone to anomalies in dental structures. Cone-shaped and taurodontic teeth were observed. Multiple tooth agenesis (mainly at premolars and molars) with over-retained deciduous dentition might be associated with MSX1-gene impairment (Adv Clin Exp Med 2014, 23, 3, 485-489).
\end{abstract}

Key words: 4p16.3 deletion syndrome, Wolf-Hirschhorn syndrome, MSX1 mutation, facial features.

Wolf-Hirschhorn syndrome (WHS) is a congenital disorder caused by microdeletion of the short arm of chromosome 4 (del 4p16.3) encoding MSX1 gene. The critical region for WHS is confined as $165 \mathrm{~kb}$. The sequence of syndromes was first described by Hirschhorn and Cooper in 1961. The first description applied to an individual with a disturbed midline fusion resulting from a deletion of the short arm of the group B chromosome. The genetics were not well developed at that moment, so no sooner than when Lejeune et al. described the cri du chat syndrome as a partial deletion of chromosome 5, that it turned out the patient described by Hirschhorn and Cooper was characterized with other symptoms [1-5]. The vast majority of cases are caused by a deletion of $4 \mathrm{p} 16.3$ regio, especially among Wolf-Hirschhorn candidate genes or, so called, critical regions (WHSC1 and WHSC2) $[1,3,6]$. Small deletions are easier to diagnose than distal deletions [1]. Ca. $85 \%$ of cases are caused by de novo deletion, while the rest is caused by an unbalanced translocation within the 4 p16 chromosome. The majority of cases concern a "pure" deletion of a part of te short arm of chromosome 4 , the rest of them are caused by a deformity within the chromosomal structure (ring chromosome, mosaicism or translocation) $[4,7]$. The rest of the cases are inherited with a translocation within the chromosome [8]. Rarely, a duplication of 4 p16 is observed [5].

Lately, it had been shown that the WHSC1 gene localizes to sites of DNA damage and replication stress and is required to inhibit the DNA damage. WHSC1 is responsible for the regulation of methylation of histone $\mathrm{H} 4 \mathrm{~K} 20$ residue, which is required for the junction of 53BP1 to sites of DNA damage. This leads to the thesis that Wolf-Hirschhorn syndrome might be the cause of DNA damage response (DDR) [6]. The importance of DDR is observed in the fact that the DNA repair impairment may lead to developmental defects, immunodeficiency, neurological problems and cancer $[9,10]$. WHSC1 mutation most likely does not directly lead to the response in DNA damage, but prologues the required genetic response. Moreover, the WHSC1 is required for recruitment or retention of $\mathrm{p} 53$-binding protein 1 (53BP1) at DNA damage sited. The recruitment is not fully understood yet, aside from the fact that WHSC1 plays a crucial role in DNA damage response, and is therefore involved in human development and neuronal homeostasis. Its deletion leads to increased levels of DNA damage [6]. 
The $\mathrm{t}(4 ; 14)(\mathrm{p} 16.3 ; \mathrm{q} 32.3)$ chromosomal translocation (that also targets WHSC1 gene) results in the overproduction of WHSC1 protein in myelomas [6].

Birth incidence is stated at least $1: 50,000$ births and might be higher due to diagnostic difficulties. It occurs two times more frequently in females [11-13]. The more chromosomal material is missing, the larger expression of WHS is observed in patients [7]. The WHS is also known as chromosome deletion Dillan 4p syndrome [11].

Beside the Wolf-Hirschhorn syndrome, MSX1 gene is known from its most common mutation that is found to be (next to PAX9 gene) one of the most frequent causes of congenitally missing teeth (most frequently lateral upper incisors) and cleft deformities. The mutation in those cases usually refers to $4 \mathrm{p} 16.1$ locus [14-16].

\section{Congenital Defects}

Hypospadias, congenital heart diseases, renal and ophthalmic defects (such as iris coloboma, microphthlmia, strabismus - crossed eyes) and skeletal anomalies (concerning limbs and skeletal development retardation) are often observed in patients with WHS. A typical deformity is a sacral dimple - a dimple on the lower part of spine. Hernia diaphragmatica and omphalocele are also observed. A typical complication is epilepsy $[1,4]$. Mental retardation is also one of the characteristics [2].

Children with WHS present growth and developmental retardation, but also high mortality (ca. 30\%) in first two years of life. The most common causes of death were: lower respiratory tract infection, multiple congenital anomalies, sudden unexplained death and congenital heart disease. Death occurs more frequently in patients with larger deletions. It had been proven that the larger deletion, the more severe congenital deformities one presents $[1,12,17]$. The other congenital defects include muscle hypotonia and urinary tract malformations (such as renal agenesis, oligomeganephronia, bladder exstrophy, cystic dysplasia/hypoplasia and obstructive uropathy) [18].

Respiratory infections (including aspiration pneumonia, otitis media, sinusitis or chronic cough) are very common finding in patients with WHS. This is caused by the muscular hypotonia, gastroesphegal reflux and recurrent aspiration [8]. Hypotonia may also result in swallowing difficulties and other gastrointestinal disorders (including hepatic adenomas) [19].

Children also suffer from immunodeficiency (including IgA and IgG2 subclass deficiency with a normal T-cell immunity). This manifests itself with common variable immunodeficienvy (CVID) and hypogammaglobulinemia. This suggests that patients with WHS represent mutations within the B-cell (CD19) system gene [6, 8].

The most common symptoms observed in WHS are summarized in Table 1.

\section{Facial and Dental Features}

Characteristic facial features in patients with WHS are prominent glabella, high arched eyebrows and hypertelorism. Scalp defects and cranial

Table 1. Characteristic features in Wolf-Hirschhorn Syndrome

\begin{tabular}{|l|l|}
\hline Branch of medicine & Symtoms \\
\hline Otolaryngology & $\begin{array}{l}\text { dysplatic ears, periauricular tags, deafness (cochlear), infections of respiratory tract, recurrent } \\
\text { otitis, protruded eyes }\end{array}$ \\
\hline Ophthalmology & ocular hypertelorism, extropia, blepharoptosis, colobomata of the iris, microphthalmia, strabismus \\
\hline Gastroenterology & swallowing difficulties, gastroesophegal reflux, hepatic adenomas \\
\hline Cardiology & congenital heart defects \\
\hline $\begin{array}{l}\text { Orofacial Surgery } \\
\text { \&entistry }\end{array}$ & $\begin{array}{l}\text { microcephaly, micrognathia, "Greek warrior helmet" appearance (broad bridge of nose), short } \\
\text { philtrum, prominent glabella, high arched eyebrows, retardation in dental development, cranial } \\
\text { asymmetry, cleft lip and/or palate, high forehead, wide mouth with short upper lip, cone-shaped } \\
\text { teeth, hypodontia }\end{array}$ \\
\hline Dermatology & $\begin{array}{l}\text { epicanthal folds } \\
\text { seizures, epilepsy, mental retardation, muscular hypotonia }\end{array}$ \\
\hline Neurology & $\begin{array}{l}\text { growth retardation, hypospadias, renal anomalies (renal agenesis, bladder exstrophy etc.), } \\
\text { immunodeficiency (IgG, IgA), retardation of skeletal development, "sacral dimple", scoliosis, } \\
\text { high mortality, scalp defects }\end{array}$ \\
\hline
\end{tabular}


asymmetry are also observed, as well as a broad nasal bridge and a short philtrum. The maxilla is often underdeveloped (characteristic micrognathia) and may be associated with cleft lip and/or palate [1]. Other characteristic craniofacial features are high forehead, protruding eyes and epicanthal folds. The mouth is distinct and wide with downturned corners and short upper lip. The whole craniofacial complex takes a characteristic look called "Greek warrior helmet" [20, 21]. "Greek warrior helmet appearance" refers mainly to the broad bridge of the nose, which continues to the forehead and microcephaly with high forehead. The nose is coracoid. Those characteristics are more pronounced during infancy [22, 23]. Cleft defects are observed in almost half of the cases [24]. Patients also suffer from ear deformations and cochlear hearing loss [25].

In most of the cases, the dental status does not differ from that of the rest of society. The inflammation within periodontium might be caused by improper oral hygiene due to the mental retardation of the individuals. Dellavia et al. [26] reported that a patient had cone-shaped teeth only in one case, while all other patients presented normal tooth shape and seizure. Due to the MSX1 anomalies in this syndrome, multiple tooth agenesis concerning mainly premolars and molars (including oligodontia) had been reported. Due to the lack of tooth buds, over-retained primary teeth are observed. Among various tooth anomalies, also taurodontism had been reported [27-29]. Another characteristic might be late dental development, which is specified as delayed tooth eruption and slower maturation expressed in dental age [30]. There had been observations of taurodontism, which is a dental trait, in which the dental pulp chambers are elongated and the bifurcation or trifurcation is displaced to the dental root apex. This also may influence dental eruption retardation with more difficulties due to larger tooth dimensions [31].

\section{Differential Diagnosis}

The initial diagnosis is given based on facial features after the birth. Some suggestions of WHS might occur with the observation of developmental retardation [22]. The final diagnosis is stated on the basis of a genetic examination. In WHS it is difficult, as gene(s) defect(s) in this case are unknown. There are some candidate genes. Among them the most commonly named are WHSC1, WHSC2 and fibroblast growth factor receptor 3 - FGFR 3 [32]. The only confined critical region is $165 \mathrm{~kb}$. Several microdeletions (such as Rubinstein-Taybi syndrome with deletion of $16 \mathrm{p} 13.3$ or Smith-Magenis syndrome with deletion of 17p11.2) should be excluded [4].

Most of the problems of differential diagnosis concern the Pitt-Rogers-Danks syndrome. The syndrome is caused by microdeletions in locus 4 p16.3 and might be a clinical variation of WHS. In some cases the names are used interchangeably [24] while other authors argue whether they are the same clinical entities [33]. The symptoms of those two are almost the same, but in Pitt-Rogers-Danks syndrome they have a milder expression [24].

Other similar anomaly might be the Opitz G/ /BBB syndrome, which is also a midline malformation syndrome. The characteristics are hypertelorism, hypospadias, clefts, developmental delay, cardiac defects as well as laryngotracheoesophageal abnormalities and an imperforate anus. In this case a differential diagnosis includes genetic examination - Opitz G/BBB syndrome is associated with MID1 mutation within the X-linked form, but unfortunately, the genes responsible for an autosomally dominant form had not been identified yet [34].

The skeletal anomalies, limited fetal growth, as well as hypospadias in males can be observed in the fetus during an ultrasound examination performed in the third trimester, and can be confirmed by a genetic examination during the pregnancy [35]. The more chromosomal material is missing, the easier it is to state the diagnosis, as a more severe syndrome is observed [7]. The prenatal diagnosis can be very difficult. Observation of prefrontal edema and other facial anomalies in fetus associated with growth retardation (even a borderline) should alert a gynecologist to investigate the $4 \mathrm{p}$ - deletion [22].

\section{Conclusions}

Wolf-Hirschhorn syndrome is a rare congenital defect, in which the deletion of part of short arm of chromosome 4 (especially MSX1 gene) takes place. The diagnosis is difficult and due to a large diversity of expression of syndrome, some of the cases might be missing. To detect the anomaly FISH method of genotype screening is used.

MSX1 takes most of its expression in mesenchyme and its mutations are involved in changes in ectodermal and mesodermal structures. The mutations within the MSX1 gene are not a rare aspect and result in hipodontia (congenital lack of tooth buds) and cleft deformities. It is also involved in WHS, Witkop syndrome and Pierre Robin syndromes, though mutations might be present in other congenital deformities and may accompany them. Therefore, the gene might be interesting for further studies [8, 36-38]. 


\section{References}

[1] Shannon NL, Maltby EL, Rigby AS, Quarrell OWJ: An epidemiological study of Wolf-Hirschhorn syndrome: life expectancy and cause of mortality. J Med Genet 2001 38, 674-679.

[2] Hirschhorn K, Cooper HL: Apparent deletion of one chromosome (4 or 5) in a child with defects of midline fusion. Hum Chrom News 1961, 4, 14.

[3] Wright TJ, Ricke DO, Denison K, Abmayr S, Cotter PD, Hirschhorn K, Keinanen M, McDonald-McGinn D, Somer M, Spinner N, Yang-Feng T, Zackai E, Altherr MR: A transcript map of the newly defined 165kb WolfHirschhorn syndrome critical region. Hum Mol Genet 1997, 6, 317-324.

[4] Stec I, Wright TJ, van Ommen GJB, de Boer PAJ, van Haeringen A, Moorman AF, Altherr MR, den Dunnen JT: WHSC1, a $90 \mathrm{~kb}$ SET domain containing gene, expressed in early development and homologous to a Drosophila dysmorphy gene maps to theWolf-Hirschhorn syndrome critical region and is fused to $\operatorname{IgH}$ in $\mathrm{t}(4 ; 14)$ multiple myloma. Hum Mol Genet 1998, 7, 1071-1082.

[5] Eastbrooks LL, Breg WR, Hayden MR, Ledbetter DH, Myers MR, Wyandt HE, Yang-Feng TL, Hirschhorn K: Summary of the 1993 ASHG ancillary meeting "recent research on chromosome 4p syndromes and genes. Am J Med Genet 1995, 55, 453-458.

[6] Hajdu I, Ciccia A, Lewis SM, Elledge SJ: Wolf-Hirschhorn syndrome candidate 1 is involved In the cellular response to DNA damage. Cell Biol 2011, 108, 13130-13134.

[7] Sifakis S, Manolakos E, Vetro A, Kappou D, Peitsidis P, Kontodiou M, Garas A, Vrachnis N, Konstandinidou A, Zuffardi O, Orru S, Papoulidis I: Prenatal diagnosis of Wolf-Hirschhorn syndrome confirmed by comparative genomic hybridization array: report of two cases and review of the literature. Mol Cytogenet 2012, 5, 12.

[8] Hanley-Lopez J, Estabrooks LL, Stiehm R: Antibody deficiency in Wolf-Hirschhorn syndrome. J Pediatr 1998, $133,1,141-143$.

[9] Jackson SP, Bartek J: The DNA-damage response in human biology and disease. Nature 2009, 461, 1071-1078.

[10] Ciccia A, Elledge SJ: The DNA damage response: Making it safe to play with knives. Mol Cell 2010, 40, 179-204.

[11] Shannon NL, Maltby EL, Rigby AS, Quarrell OWJ: An epidemiological study of Wolf-Hirschhorn syndrome: life expectancy and cause of mortality. J Med Genet 2001, 38, 674-679.

[12] Wieczorek D, Krause M, Majewski F, Albrecht B, Horn D, Riess O, Gillessen-Kaesbach G: Effect of the size of the deletion and clinical manifestation in Wolf-Hirschhorn syndrome: analysis of 13 patients with a de novo deletion. Eur J Hum Genet 2000, 8, 519-526.

[13] Zollino M, Lecce R, Fischetto R, Murdolo M, Faravelli F, Selicorni A, Buttè C, Memo L, Capovilla G, Neri G: Mapping the Wolf-Hirschhorn syndrome phenotype outside the currently accepted WHS critical region and defining a new critical region, WHSCR-2. Am J Hum Genet 2003, 75, 590-597.

[14] Mielnik-Błaszczak M, Piątkowska A, Machowska A, Bukowska B: Tooth Genesis - a review of literture and own case studies. Dent Med Probl 2012, 49, 293-298.

[15] Rychlik D, Wójcicki P, Koźlik M: Osteoplasty of the alveolar cleft defect. Adv Clin Exp Med 2012, 21, $255-262$.

[16] Jędryszek A, Kmiecik M, Paszkiewicz A: review of modern knowledge on hypodontia. Dent Med Probl 2009, 46, $118-125$.

[17] Elder FFB, Colasurdo GN, Rose VM: Wolf-Hirschhorn-Pitt-Rogers-Danks phenotype with no detectable deletion. Am J Hum Genet 2000, 67, Suppl 2, 119.

[18] Lurie IW, Lazjuk GI, Ussova YI, Presman EB, Burevich DB: The Wolf-Hirschhorn syndrome. I. Genetics. Clin Genetics 1980, 17, 6, 375-384.

[19] Prutta G, Cianci P, Cereda A, Scatigno A, Fossati C, Maitz S, Biondi A, Selicorni A: Two cases of hepatic adenomas in patients with Wolf-Hirschhorn syndrome: a new rare complication? Am J Med Genet 2013, 1759-1765.

[20] Battaglia A, Filippi T, Carey JC: Update on the clinical features and natural history of Wolf-Hirschhorn (4p-) syndrome: experience with 87 patients and recommendations for routine health supervision. Am J Med Genet (Semin Med Genet), 2008, 148, 246-251.

[21] Pitt DB, Rogers JG, Dank, DM: Mental retardation, unusual face, and intrauterine growth retardation: a new recessive syndrome? Am J Med Genet 1984, 19, 307-313.

[22] Levaillant JM, Touboul C, Sinico M, Vergnaud A, Serero S, Druart L, Blondeau JR, Abd Alsamad I, Haddad B, Gerard-Blanluet M: Prenatal forehead edema in 4p-deletion: the "Greek warrior helmet" profile revisited. Prenat Diagn 2005, 25, 1150-1155.

[23] Laziuk GI, Ostrovskasia TI, Lur IV, Kirillova IA, Kravtsova GI: Pathologic anatomy of the Wolf-Hirschhorn syndrome Partial monosomy (4p-). Arkh Patol 1979, 41, 8, 40-45.

[24] Battaglia A, Carey JC, Cederholm P, Viskochil DH, Brothman AR, Galasso C: Natural history of Wolf-Hirschhorn syndrome: experience with 15 cases. Pediatrics 1999, 103, 830-836.

[25] Battaglia A, Filippi T, Carey JC: Update on the clinical features and natural history of Wolf-Hirschhorn (4p-) syndrome: Experience with 87 patients and recommendations for routine health supervision. Am J Med Genet Part C Semin Med Genet 2008, 148, 246-251.

[26] Dellavia X, Raiteri S, Ottolina P, Pregliasco F: Oral features in five adult patients with Wolf-Hirschhorn syndrome. Minerva Stomatol 2011, 60, 7-8, 391-402.

[27] Nieminen P, Kotilainen J, Aalto Y, Knuutila S, Pirinen S, Thesleff I: MSX1 gene is deleted in Wolf-Hirschhorn syndrome patients with oligodontia. J Dent Res 2003, 82, 12, 1013-1017.

[28] Modesto A, Moreno LM, Krahn K, Lidra AC: MSX1 and orifacial clefting with and without tooth agenesis. J Dent Res 2006, 85, 542-546. 
[29] Babich SB, Banducci C, Teplitsky P: Dental characteristics of the Wolf-Hirschhorn syndrome: a case report. Spec Care Dentist 2004, 24, 4, 229-231.

[30] Johnston NJ, Franklin DL: Dental findings of a child with Wolf-Hirschhorn syndrome. Int J Paediatr Dent 2006, $16,2,139-142$.

[31] Breen GH: Taurodontism, an unreported dental finding in Wolf-Wirschhorn syndrome (4p- syndrome) ASDC J Dent Child 1998, 65, 5, 344-345.

[32] Basilico C, Moscatelli D: The FGF family of growth factors and oncogenes. Adv Cancer Res 1992, 59, 115-165.

[33] Wright TJ, Altherr MR, Callen D, Hirschhorn K: Reply to the letter to the editor by Partington and Turner'Wolf-Hirschhorn and Pitt-Rogers-Danks syndrome'. Am J Med Genet 1999, 82, 89-90.

[34] So J, Müller I, Kunath M, Herrmann S, Ullmann R, Schweiger S: diagnosis of a terminal deletion of 4p with duplication of Xp22.31 in a patient with findings of Opitz G/BBB syndrome and Wolf-Hirschhorn syndrome. Am J Med Genet A 2008, 1, 146, 1, 103-109.

[35] Aslan H, Karaca N, Basaran S, Ceylan Y: Prenatal diagnosis of Wolf-Hirschhorn syndrome (4p-) in association with congenital hypospadias and foot deformity. BMC Pregnancy Childbirth 2003, 24, 3, 1, 1 .

[36] Abu-Hussein M: Cleft Lip and Palate - etiological factors. Dent Med Probl 2012, 49, 149-156.

[37] Jumlongras D, Bei M, Stimson JM, Wang WF, DePalma SR, Seidmn CE, Felbor U, Maas R, Seidmen JG, Olsen BR: A nonsense mutation in MSX1 causes Witkop syndrome. Am J Hum Genet 2001, 69, 67-74.

[38] Mostowska A, Biedziak B, Jagodziński PP: Analysis of the coding sequence of the MSX1 and PAX9 genes in patients with congenital lack of permanent teeth. Dent Med Probl 2012, 49, 157-165.

\section{Address for correspondence}

Anna M. Paradowska-Stolarz

Department of Dentofacial Anomalies

Department of Orthodontics

Wroclaw Medical University

Krakowska 26

50-425 Wrocław

Poland

E-mail: anna.paradowska-stolarz@umed.wroc.pl

Conflict of interest: None declared

Received: 1.01.2014

Revised: 13.02.2014

Accepted: 27.05.2014 